\title{
Fabrication of Patterned Fluorescence Images in Electrospun Microfibers
}

\author{
Cheol Hee Lee and Jong-Man Kim*
}

\author{
Department of Chemical Engineering, Hanvang Lniversitv. Seoul 133-791, Korea. ${ }^{*}$ E-mail. jmkiâhamang.achr \\ Received March 26, 2008
}

Key Words : Electrospinuing, Fluorescence patterning, Photo acid generator (PAG). Microfiber

Recently. generation of patterned fluorescence images based on the "precursor approach" has gained much attention. $^{\text {l-11 }}$ The concept of the 'precursor approach' is to use different electronic properties between the protected and unprotected forms. For example, a dye molecule is nonfluorescent when the key functional group of the dye molecule is protected with a protecting group. If the protecting group is removed under photoinduced chemical transformation, the fluorescence can be regenerated. allowing pattemed fluorescent inages in the polymer film by selective removal of the protecting group in the exposed areas. The "precursor approach" allows rapid and costeffective generation of patterned inages in one step, without the need for additional wet developing processes.

We have previously reported that the fluorescent quinizarin molecule can be readily converted to a nonfluorescent protected molecule $t$-BocQ by introduction of acid-labile tert-butoxycarbonyl ( $t$-Boc) groups to the quinizarin hydroxyl moieties ${ }^{1}$ (Scheme 1). ${ }^{8}$ When the $t$-Boc groups were selectively removed by photogenerated acids, yellow fluorescent patterns were appeared in the UV exposed areas. Thus. the nonfluorescent $t$-BocQ precursor molecule was transformed to unprotected quinizarin by the photoinduced chemical transformation.

The vast majorities of the fluorescence patterns generated based on the "precursor approach" have been fabricated in polymer filnt. During the course toward the developnent of fiber-based chemosensor systemis. ${ }^{12}$ we have discovered a new strategy for the fabrication of pattenned fluorescence images in microfibers. The key strategy and procedure employed for the fluorescence patterning is schematically presented in Figure 1. A viscous chloroform solution containing the precursor molecule $t$-BocQ $(1.3 \mathrm{wt} \%)$. poly(methyl methacrylate) (PMMA) (19.6 wt \%), and a photoacid generator (PAG), triphenylsulfonium triflate $(0.6 \mathrm{wt} \%)$ is placed in a syringe. A high voltage $(18 \mathrm{kV})$ is then applied to the metal syringe needle causing ejection of a charged<smiles>O=C1c2ccccc2C(=O)c2c(O)ccc(O)c21</smiles>

Quinizarin fluorescent

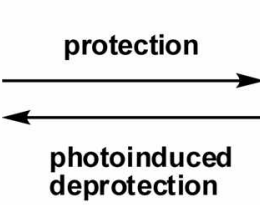
deprotection polymer jet from the polymer solution. ${ }^{13}$ The microfibers are collected on the surface of a grounded aluminum plate (15 $\mathrm{cm}$ from the needle). A scamning electron microscope (SEM) inage confirms the formation of microfibers (Figure 1). Photomasked UV irradiation of the electrospun fiber should generate strong acids from the PAG in the exposed areas. The photochemically produced strong acids should promote catalytic deprotection of the $t$-Boc groups from the precursor molecules, allowing pattened fluorescence inages in the polymer fibers.

In order to investigate the feasibility of fluorescence patteming, the polymer fiber mats obtained as described above were irradiated with $254 \mathrm{~nm}$ UV light through a photomask for $2 \mathrm{~min}$. The UV-treated fiber mats were then placed on a hot plate $\left(100^{\circ} \mathrm{C}\right)$ for $1 \mathrm{~min}$ for a post-exposure
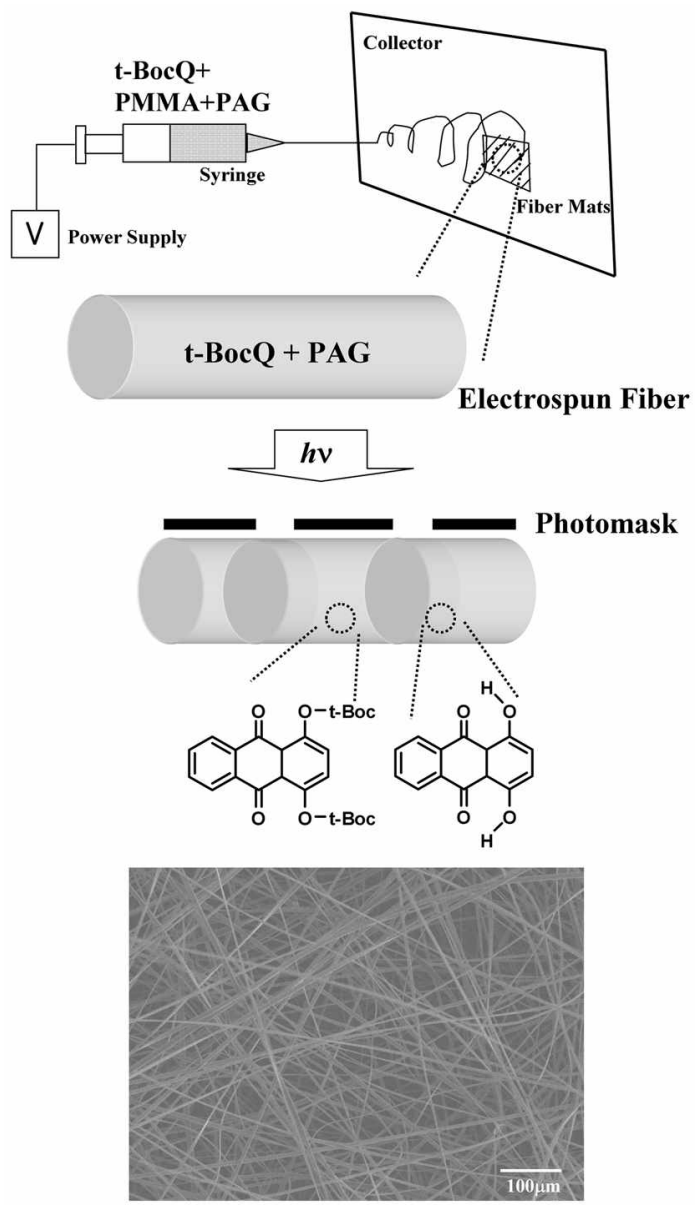

Figure 1. Schematic representation of the fabrication of fluorescence patterns in electrospun microfibers (top). SEM image of the electrospun microtibers (bottom ).

Scheme 1. Structure of quinizarin and its $t$-Boc protected tom, $t$ BocQ. 


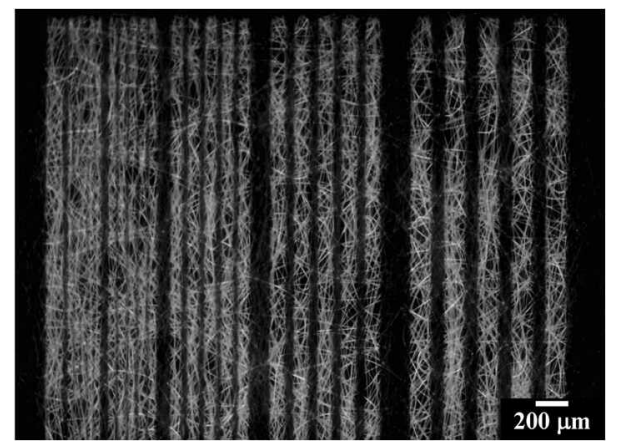

Figure 2. Pattemed fluorescence images obtained from photomasked UV irradiation $\left(254 \mathrm{~mm}, 1 \mathrm{~mW} / \mathrm{cm}^{2}, 2\right.$ min) followed by $\mathrm{PEB}\left(100^{\circ} \mathrm{C}, 1 \mathrm{~min}\right)$ of a $t$-BocQ containing electrospun fiber mat.

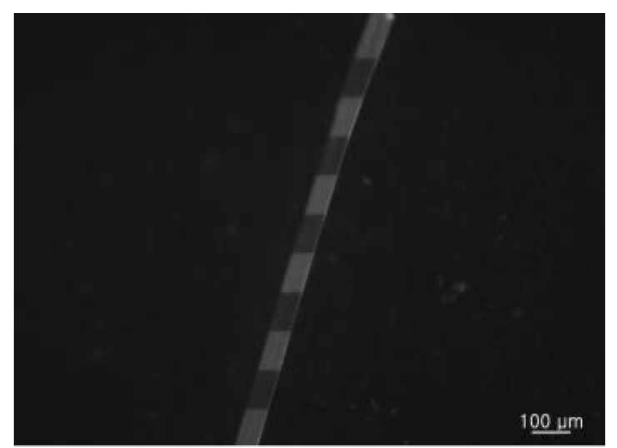

Figure 3. Patterned fluorescence images obtained from photomasked UV irradiation $\left(254 \mathrm{~mm}, \mathrm{l} \mathrm{mW} / \mathrm{cm}^{2}, 2 \mathrm{~min}\right)$ followed by $\mathrm{PEB}$ $\left(100^{\circ} \mathrm{C}, \mathrm{I}\right.$ min) of a $\mathrm{t}$-BocQ containing single electrospun fiber.

baking (PEB). In Figure 2 are displayed fluorescence microscopic inages of the UV-irradiated and heated fiber mats. Interestingly, bright yellow fluorescence signals were observed only from the UV-exposed areas, indicating successful and selective transformation of the $t$-Boc protected precursor molecule to the original unprotected quinizarin in the polymer fibers.

We also explored fluorescence patteming in a single electrospun fiber. If pattemed images can be created photolithographically in a single fiber. the strategy can be potentially employed to introduce other functional groups into the polymer fiber. In order to investigate the feasibility of fluorescence pattering in a single polymer fiber. the $t$-BocQ containing single electrospun fiber was placed under a photomask and was subjected to the UV irradiation-PEB process. As displayed in Figure 3, yellow fluorescence patterns can be clearly seen under a fluorescence microscope.

In order to measure the yield of the $t$-Boc protected quinizarin to its unprotected quinizarin in the electrospun fibers. the precursor-embedded fiber mat was irradiated with UV light for $2 \mathrm{~min}$ without using the photomask. The resultant fiber mat was dissolved in chloroform and the UVvisible spectnum of the chloroform solution was recorded (Figure 4a). To this chloroform solution was added trifluoroacetic acid $(20 \%, \mathrm{v} / \mathrm{v})$ and the solution was stirred for $60 \mathrm{~min}$ to remove the residual $t$-Boc groups. After concentration in vacuo. the residue was dissolved in chloroform and UV-visible spectnum was monitored (Figure 4 b). The ab-

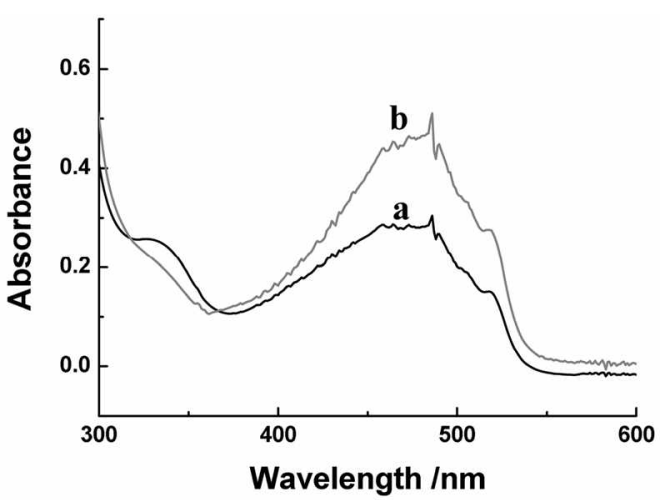

Figure 4. UV-visible spectra of chloroform solutions obtained from UV irrdiaton (254 mm, $1 \mathrm{~mW} / \mathrm{cm}^{2}, 2$ min) followed by PEB (100 ${ }^{\circ} \mathrm{C}, 1$ min) of a $t$-BocQ-embedded electrospun tïber mat before (a) and after (b) treatment of trifluoroacetic acid.

sorption difference at $480 \mathrm{~nm}$ allows calculation of the yield of quinizarin and is found to be $61 \%$. Thus, fairly significant amounts of the precursor molecules were converted to quinizarin in the electrospun fibers.

In sunmary, we have developed a new and straightfonvard strategy for the generation of pattemed fluorescence images in microfibers. By employing the photolithographic technique, we were able to create patterned fluorescence images in polymer fibers based on a $t$-Boc protected quinizarin as a precursor molecule. Considering the significance of the fluorescence patterning technology in the field of sensor, molecular switch as well as menory device and display areas. the results described above should find great utility in those areas. In addition, photolithographic method for patterned images in a single microfiber should be useful for selective introduction of functional groups to the polymer microfibers.

Acknowlegments. This work was supported by the research fund of Hanyang University (HY-2007-I).

\section{References}

1. For recent review see: Kim. T.-M. Macronol. Rapid Conmum. 2007. 28,1191

2. Lim. S.J.; Seo, J.; Park. Y. J. Am. Chem. Soc. 2006. $128,14542$.

3. Lee. J. K. Kim, H.-J; Kim. T. H.: Lee. C.-H; Park. W. H.: Kim. J.: Lee. T. S. Hachonolecules 2005. 38.9427.

4. Kwak. G.: Fujiki. M.: Sakaguchi. T.: Masuda. T. Macrontolectles 2006. 39.319.

5. Irie. M.: Fukaminato. T.: Sasaki, T: Tamai, N. Kawai, T. Fatme? 2002. 420,759

6. Scaiano, J. C. Laferriere, M: Ivan. M. G. Taylor, G. N. Haconolecules 2003. 36.6692.

7. Zhang. C.: Vekselmant. A. M.: Darling. G. D. Chem. Mater. 1995. 7.850

8. Kim. J.-M: Kang, J.-H; Han, D. K; Lee. C.-W.: Ahn. K.-D. Chem. Hater: 1998, 10. 2332.

9. Kocher. C.: Smith, P.: Weder C. J. Mater Chem 2002. 12. 2620.

10. Beltield. K. D.: Schater. K. J. Chent Mater 2012. Jt. 3656.

11. Kim. J-M.: Min. S. J.: Lee. S. W.: Bok. J. H.: Kim. T.-S. Chent. Contmitm. 2005. 3427

12. Yoon, J.; Chae, S. K.: Kim, J.-M. J. Am. Chem. Soc. 2007. 129.3038.

13. For recent review on electrospinning technique. see: Dzenis. Y. Science 2004. 304, 1917. 